\title{
CENTRO E PERIFERIA NA PRODUÇÃO E AVALIAÇÃO DA OBRA DE GILVAN SAMICO
}

\section{CENTER AND PERIPHERY IN THE PRODUCTION AND EVALUATION OF THE GILVAN SAMICO ARTISTIC WORKS}

\author{
Eduardo Dimitrov
}

\section{Introdução}

Em seu Atlas do Romance Europeu, livro basilar nos estudos sobre geopolítica da produção cultural, Franco Moretti constata um funcionamento peculiar das periferias do sistema literário. Inspirado na teoria do subdesenvolvimento econômico de Gunnar Myrdal (1956), a periferia cultural não seria uma réplica reduzida ou atrasada em relação ao centro, mas possuiria uma dinâmica própria de funcionamento. 0 desenvolvimento do subdesenvolvimento literário é regido por regras específicas, muitas vezes diversas daquelas que ordenam o desenvol- vimento dos centros.

Apoiado em inúmeros exemplos, inclusive no caso brasileiro descrito por Roberto Schwarz (2000a, 2000b), Moretti percebe, olhando seus mapas, a dinâmica de exportação de modelos literários do centro em direção às periferias e o esforço que elas fazem para incorporar os moldes literários adequando-os às realidades locais.

Afasta, desse modo, uma abordagem mais ingênua para a qual a história da arte seria uma história de centros sucessivos, dos quais se irradiariam, para as províncias, as inovações de estilo. 0 centro concentraria um público mais exigente, artistas

\footnotetext{
* Professor do Departamento de Sociologia da Universidade de Brasília - UNB - (Brasília/DF/Brasil).

Doutor em Antropologia Social pela FFLCH/USP. E-mail: edu@dimitrov.com.br.
} 
mais habilidosos, um estilo metropolitano. As províncias, por sua vez, teriam públicos menos cultivados, artistas menos habilidosos, estilo provinciano.

Moretti identifica que nada disso é inteiramente equivocado, porém, acrescenta o conflito nessa equação:

[...] o provincianismo não é tanto uma questão de diferença do centro, mas de semelhança forçada: a convicção de que a vida "real" só deve ser vivida em Paris (ou Londres, ou Moscou) - enquanto a vida nas províncias é simplesmente uma sombra. Os romances que chegam do centro, tendo a malaise provincial como um de seus temas favoritos, reforçam o círculo de dependência repetidas vezes (MORETTI, 2003, p. 175 grifos do autor).

Pouco mais à frente, completa:

Não difusão mas conflito, então. Ou, melhor, difusão enquanto conflito: entre os romances que vêm do centro e as formas culturais que são mais típicas das editoras provinciais (MORETTI, 2003, p. 177).

Semelhança forçada, difusão enquanto conflito são algumas das chaves possíveis para se interpelar a obra gravurista Gilvan Samico célebre por sua alta qualidade técnica e associação ao Movimento Armorial encabeçado, nos anos 1970, pelo escritor e dramaturgo Ariano Suassuna.

Neste artigo, não trabalharei com mapas, nem com literatura, mas com a relação centro e periferia na produção e trajetória artística de Gilvan Samico. Pernambucano de nascimento (1928), Samico morou em São Paulo e no Rio de Janeiro, onde teve aulas com importantes figuras da gravura nacional, além de ter feito longa viagem pela Europa. Retornou à Olinda em 1965, de onde nunca mais se ausentou, falecendo em 2013. Foi de Olinda que Samico se consagrou como gravurista e alcançou certo reconhecimento da crítica especializada. É esse percurso tensionado, de semelhanças forçadas e difusões conflituosas, que tentarei reconstruir nas próximas páginas.

\section{Anos de formação}

Gilvan Samico iniciou seus estudos no Atelier Coletivo, grupo encabeçado, em 1952, pelo escultor comunista Abelardo da Hora que defendia a formação de uma arte "eminentemente brasileira”. Seria preciso, portanto, formar jovens artistas atentos à realidade do "povo" e às manifestações populares. Foi com esse espírito que Abelardo criou primeiramente um curso de desenho e, em seguida, o Atelier Coletivo.

0 curso de desenho ocorria em uma das salas do Liceu de Artes e Ofícios emprestada a Abelardo graças aos contatos de seu irmão Bianor, Presidente da Sociedade de Cultura Estevão Cruz, formada por ex-alunos do Ginásio Pernambucano. Em um dado momento, a diretoria do Liceu pede a sala de volta inviabilizando o curso.

Os alunos, todos jovens, organizaram-se para montar um Atelier Coletivo no qual cotizavam as despesas de aluguel e material de pintura. Nenhum dos primeiros integrantes era artista profissional; mantinham seus empregos em outros ramos e frequentavam o Atelier em seu tempo livre. Esse era o caso de Gilvan Samico, José Cláudio, Wellington Virgolino, Wilton de Souza, Ionaldo Cavalcanti. Foi apenas no final dos anos 1950 e início dos 1960 que alguns dos integrantes do grupo conseguiriam sua autonomia financeira por meio da venda de suas obras. 
Por intermédio de seu cunhado, o então deputado estadual Augusto Lucena ${ }^{1}$, e de outros políticos, Abelardo da Hora conseguiu uma pequena verba ao grupo e, logo em seguida, um decreto reconhecendo sua utilidade pública. Parece que parentes políticos de Ionaldo Cavalcanti também colaboraram para o mesmo fim; um tio de Samico teria sido o fiador das salas alugadas. Esses auxílios não resolviam todos os problemas do grupo, mas forneciam condições mínimas para seguirem trabalhando.

Nesse período, Samico produziu telas não muito distintas das de seus colegas, como a Pescadores de Siri na Ponte Velha (Figura 1), na qual três homens negros são representados em uma atividade típica das populações mais carentes do Recife - a pesca em área urbana. Ou ainda o quadro Trabalhadores, de 1954, (Figura 2), em que retrata dois homens vendendo frutas em um ambiente luminoso e brincando com formas geométricas das barracas de uma feira, em primeiro plano. Colocar a população pobre e trabalhadora no centro das telas era uma orientação de Abelardo para o grupo de jovens artistas. Também nesse período, Samico inicia-se na gravura com a experiência do Clube de Gravura organizado pelo Atelier Coletivo. Lembra ele este período:

Abelardo em determinado momento fundou, a exemplo de outros, o clube da gravura, (...) [a] tiragem era vendida ou distribuída com os sócios (...). Eu acho que a primeira gravura que saiu foi a minha ${ }^{2}$. Muito bem, então eu fiz a gravura, uns pescadores, feito numa placa de gesso, porque Abelardo usava muito gesso e achou que a gente devia gravar em gesso, tinha lá suas razões porque fundia uma plaquinha em cima de um vidro, já saía polida, já saía... bom, um horror, fiz uma para nunca mais. (...) cheguei a dizer: mas Abelardo a gente com a floresta amazônica - e, diga-se de passagem, naquela época era muito maior - e gravando em cima de gesso, material horroroso desse, ele disse "não, é porque a madeira você tem que comprar, tem que aplainar, lixar, e esse aqui a gente já faz o gesso daqui, a gente já resolve aqui mesmo". Pois bem, eu disse que ia fazer minha gravura em madeira em casa (SAMICO; FERNANDES, 2008, p. 7).

Os argumentos que Samico recordou da discussão não mobilizavam a questão de o gesso ser considerado um material da "região", tal como Abelardo fez questão de enfatizar na apresentação do álbum de gravura de 1957. A utilização do gesso como matriz foi uma das experiências do grupo em adequar o modelo da gravura à realidade local. Descoberto no interior do estado, o gesso vinha sendo explorado economicamente, e Abelardo buscava elevar o status simbólico do material. Contrariando as orientações, foi com uma dessas gravuras em madeira feitas em casa que Samico recebeu um prêmio num dos salões do Esta-

1. Augusto Lucena (1916 - 1995) foi deputado estadual de Pernambuco nas legislaturas de 1954, 1958 e 1962; vice-prefeito, assumiu a prefeitura do Recife após o Golpe de 1964 que depôs Pelópidas da Silveira; foi vereador do Recife nas legislaturas de 1968 e 1975; voltou a ser deputado federal nas legislaturas de 1970 e 1978; foi prefeito biônico do Recife, indicado pelo então governador de Pernambuco Eraldo Gueiros Leite entre 1971 e 1975.

2. Nesse período alguns clubes de gravura surgiram no Brasil. A referência era o grupo organizado em torno de Carlos Scliar, nos anos 1950, no Rio Grande do Sul. Para mais detalhes, ver Amaral (2003) 
do de Pernambuco, animando-o a perseguir uma melhor formação.

\section{Experiências no centro}

Em 1957, durante suas férias e licença -prêmio da repartição em que trabalhava (Cf. SAMIC0; FERNANDES, 2008, p. 8), Samico instala-se em São Paulo, na casa de um primo. Toma aulas com Lívio Abramo, na Escola de Artesanato do Museu de Arte Moderna, a quem foi apresentado pelo amigo Aloísio Magalhães $^{3}$ que fora membro do júri do $S a$ lão do Museu do Estado de Pernambuco no qual foi agraciado com o prêmio. É consenso na crítica especializada a mudança que as orientações de Livio Abramo tiveram nas obras de Samico. Dedicando-se basicamente à gravura, suas imagens passam a ser mais “profundas”, como em A Mão (Figura 3), em que rostos de homens são compostos por um tracejado nervoso. E, numa zona escura no alto, com um tracejado horizontal, partes de rostos e narizes aparecem fantasmagoricamente. Na gravura A menina dos Currupius (Figura 4), o que seria uma cena lúdica de uma criança brincando com cata-ventos apresenta-se com um tom fúnebre: cabisbaixa e olhar tristonho. Em ambas, Samico esbanja um riquíssimo léxico gráfico que permite a exploração de texturas e luminosidades, algo impossível no gesso, material quebradiço que, praticamente, permite apenas o traçado de linhas. Cada sulco na madeira guarda sua especificidade, sua gestualidade, resquícios dos instrumentos utilizados.

Dificuldades financeiras levam Samico, em 1958, ao Rio de Janeiro, onde, por meio de sua rede de relações, teria mais chances de emprego. Foi Lívio Abramo quem o indicou ao colega Oswaldo Goeldi, que ministrava curso gratuito de gravura na Escola Nacional de Belas Artes. É desse ano a gravura Leitura na Praça (Figura 5), na qual quatro homens estão sentados em volta de uma árvore lendo seus jornais. Não há troca de olhares entre os personagens. Cada um está absorto em seu próprio mundo oferecido pela leitura nesse cenário urbano de uma praça pública. Essa semelhança temática já bastaria para associar suas gravuras às de seu professor Goeldi. Há, ainda, alguns aspectos formais, entre eles, a predominância do negro, rasgado apenas por alguns traços ou manchas brancas. 0 uso preciso da cor, outra característica de Goeldi, é explorado em outras imagens de Samico, por exemplo, a Dama com luvas (Figura 6).

\section{0 retorno à Olinda}

No Rio de Janeiro trabalha no escritório do designer Aloísio Magalhães, o que lhe permite ficar na cidade até 1965, quando se transfere para Olinda. Mesmo antes de seu retorno, em 1962, é acometido por uma hesitação comum aos artistas pernambucanos ${ }^{4}$. Uma espécie de inadequação de seus

3. Já então gozando de certo prestígio enquanto artista e designer gráfico, Aloísio Magalhães (1927-1982) era da mesma geração e círculo de amizades de Samico. Posteriormente, Aloísio será reconhecido como importante gestor de políticas de proteção ao patrimônio nacional.

4. Explorei essa hesitação em diferentes trajetórias artísticas em DIMITROV, E. "Regional como opção, regional como prisão: trajetórias artísticas no modernismo pernambucano". 2014. Universidade de São Paulo, São Paulo, 2014. Disponível em: <http://www.teses.usp.br/teses/disponiveis/8/8134/tde-08052014104648/>. Acesso em: 13 dez. 2018. 
trabalhos a um desejo "seu", a um ideal de "coisa brasileira” ou de "arte mais localizada”. Assim descreve Samico:

(...) mostrei [para Ariano Suassuna] as coisas que estava fazendo lá no Rio, e disse para ele: estou fazendo esse negócio, mas não estou satisfeito, porque eu acho que estou fazendo uma coisa que não corresponde a um desejo meu de ter um tipo de arte mais localizada, onde eu pudesse sentir que eu estava fazendo uma coisa mais especial, essa coisa mais brasileira. Vamos dizer, isso é um pouco complicado da gente, mas na época eu falei assim. Aí Ariano disse: "não, mas você está fazendo gravura rapaz, nós temos uma tradição da gravura popular, uma coisa tão já arraigada, já fixada, porque você não dá uma entrada nessa coisa?". E foi essa conversa que me serviu para eu poder começar elaborar uma outra coisa dentro de mim. Não aquilo que eu estava fazendo da gravura sombria, muito noturna, com...(...) não considero que minha gravura fosse expressionista, mas havia um parentesco, e daí um parentesco com a gravura europeia (SAMICO; FERNANDES, 2008).

Nessa conversa com Ariano Suassuna, ocorrida em 1962, Samico mostra-se preocupado com o fato de sua produção ser, supostamente, pouco brasileira. Uma vez estabelecido em Olinda, em 1965, de onde nunca mais se mudaria, não se sentia mais à vontade para produzir aquelas gravuras "sombrias" ou "noturnas"5. Passa então a não mais gravar a linha branca em fundo preto, como fazia Goeldi e seu "expressionismo" noturno, e sim a linha preta em fundo branco, como faziam os gravadores populares, "genuinamente brasileiros". A busca pela "brasilidade" passa a ser um ideal perseguido pelo artista. 0 problema, portanto, perpassa também a definição do que seria essa "brasilidade" genuína.

É desse período de virada, por exemplo, a gravura Tentação de Santo Antônio (Figura 7), na qual todas as figuras são desenhadas em traços pretos sobre um fundo branco. A temática religiosa; o uso do diabo no canto direito inferior bem como de outra figura pouco reconhecível - talvez outro demônio - no centro da composição em vermelho, escondido entre as folhas da copa da árvore; os animais (cabras, macacos, corujas) e a vegetação, de alguma forma remetem ao que genericamente se costuma associar ao universo popular. A fatura extremamente elaborada nada se assemelha às gravuras grosseiras dos cordéis. Samico explora de maneira virtuosística diferentes texturas aprendidas com Lívio Abramo ${ }^{6}$; seja na estampa da camisa de Santo Antônio, no agitar da água do lago central, na relva à esquerda, na pelagem das cabras, macacos e coruja. 0 uso preciso de cores confinadas, emprestadas de Goeldi, mostram-se aqui no verde do lago, no vermelho do demô-

5. Samico saiu de Pernambuco apenas entre 1968 e 1970, quando, por ter ganho o Prêmio de Viagem no $17^{\circ}$ Salão Nacional de Arte Moderna, no Rio de Janeiro, viaja à Europa.

6. Devo essa observação à exposição Gilvan Samico - primeiras estórias, realizada no Centro Cultural Maria Antônia/USP, entre fevereiro e março de 2013, organizada por Cláudio Mubarac e Priscila Sachettin, na qual gravuras de Samico foram expostas ao lado dos trabalhos de Goeldi, Abramo, Ligia Pape e de gravadores da Escola do Horto, capitaneada por Adolph Kohler. As referências de Samico na construção de seu léxico gráfico foram muito bem exploradas pelos curadores. 
nio ao centro, no amarelo-alaranjado da auréola de Santo Antônio. Aqui a noção de semelhança forçada ou de difusão enquanto conflito reaparecem. A gramática gráfica de Samico, adquirida nos grandes centros por meio dos artistas consagrados são postas em negociações com a "realidade local", com o "típico".

Essa caracterização de Samico como um artista capaz de associar a técnica e o rigor das formas dos mestres Abramo e Goeldi com um universo popular aparece recorrentemente em sua fortuna crítica. Moacir dos Anjos, então diretor do Museu de Arte Moderna Aloísio Magalhães de Recife, diz:

(...) o artista confronta as técnicas adquiridas com o universo criativo do romanceiro popular do Nordeste do Brasil. Não tanto, ou somente, com as xilogravuras que ilustram as capas dos folhetos de cordel, mas também, e principalmente, com as histórias ali contadas, as quais refundam mitos, arquétipos e lendas, atualizando um tempo que a memória não pode alcançar (ANJOS JR., 2005, p. 6).

Weydson Barros Leal, por sua vez, afırma:

Em seu caso particular, a partir da poesia de cordel e de passagens dos evangelhos [...], a imagem refunde os elos entre o sagrado e o profano, entre a terra e um mundo fabuloso onde Samico reina como soberano criador. Este mundo, conquistado hoje e a cada dia em décadas de trabalho obstinado - desde quando iniciou-se na gravura com Abelardo da Hora, então aperfeiçoando-se com os mestres Lívio Abramo e Oswaldo Goeldi -, tem raizes também nas histórias de santos e, como já disse, no terreno fervente do imaginário do cordel, mas toda música e secura dos versos de amor e morte que pa- recem nascer do calor do nordeste brasileiro são sementes delicadas para sua reinvenção (LEAL, 2005, p. 30).

Ou ainda Ferreira Gullar que, a respeito das gravuras de Samico, afirma:

A gravura de Gilvan Samico tem a simplicidade da gravura popular nordestina, que lhe deve ter servido de referência ou fonte. Mas também a sofisticação, o requinte de uma arte culta, íntegra, na qual funde-se o ético e o estético. (GULLAR, 2005, p. 57).

Sobretudo a partir do final dos anos 1960 e início dos 1970 (como nas figuras 8 e 9), Samico passa a fazer gravuras tão herméticas quanto os poemas de Ariano Suassuna. Mesmo assim, são associadas pela crítica à "cultura popular", a "mitos e arquétipos", ao mesmo tempo "brasileiros" e "universais"; ou a enigmas indecifráveis, figuras totêmicas, tempos imemoriais... Como diz Agnaldo Farias:

Operando sobre a madeira, esmerando-se em seu ofício de produzir imagens, Gilvan Samico, o mais célebre morador da velha Olinda que desde o alto e à distância contempla a frenética Recife, alheio à velocidade contemporânea que passa pelas coisas condenando-as a uma vida efêmera e evanescente, extrai das camadas mais profundas do tempo e do espaço os elementos mais duradouros; limpa-os, despoja-os de suas impurezas e reorganiza-os de modo a que eles possam continuar em direção ao futuro, à procura de quem tente decifrá-los, caindo como uma chuva leve mas persistente sobre a nossa imaginação (FARIAS, 2005, p. 26-27).

As imprecisões e os impressionismos desses comentários, bem como o poder 
que possuem para ancorar Samico em uma identidade criada para e pelo Nordeste brasileiro explicitam como os artistas plásticos e críticos colaboraram para construir uma imagem de Pernambuco como o receptáculo da identidade nacional e, ao mesmo tempo, tornaram-se dela prisioneiros.

\section{Construindo o popular}

Everardo Ramos (2008), em interessante artigo, revela o processo de invenção da xilogravura como manifestação genuína da cultura popular. Demonstra como Ariano Suassuna, entre as décadas de 1950 e 1970, elegeu, dentre as capas de cordel, aquelas ilustradas com xilogravura como sendo as detentoras de uma maior autenticidade. Muitas outras capas ilustradas com outras técnicas largamente utilizadas pelos cordelistas e estimadas pelas camadas ditas "populares", tais como a zincogravura e a fotografia, foram postas de lado pelo dramaturgo. A xilogravura era uma técnica restrita aos cordéis produzidos em Juazeiro do Norte, onde a precariedade das oficinas gráficas não permitia a gravura em zinco que, de fato, era mais abundante e valorizada pelos leitores "populares" de cordel justamente por ser capaz de conferir mais detalhes realistas, como volumes e efeito de perspectiva. Segundo Ramos, Ariano Suassuna foi um ator central para que essa técnica hegemônica e baseada na fotomecânica fosse considerada menos autêntica do que o entalhe artesanal na madeira. Com isso, a xilogravura, que achata os planos, que não confere volume às figuras, que grava apenas o essencial em traços grosseiros, foi inventada como a técnica e a estética genuinamente populares, sobretudo por envolver tecnologia rudimentar em seu processo de fabricação. 0 gosto popular pela xilogravura não se verificava empiricamente. Segundo Ramos, os maiores editores de cordel investiam na zincografia, e não em artesãos da xilogravura. Os folhetos de maior sucesso de venda eram aqueles ilustrados com técnicas que permitissem maior definição realista das imagens, e não os traços grosseiros da madeira talhada. Segundo o autor, essa visão de que o "povo" preferia a rusticidade da xilogravura apenas evidenciaria as concepções de Suassuna que associavam o "povo" ao lado mais arcaico tecnicamente.

Ora, aqui se apresenta um processo de seleção e criação de tradições capaz de vincular a xilogravura a uma identidade imaginada, popular, específica (HOBSBAWM, 1997; ANDERSON, 2008). Assim formulado, a gravura de Gilvan Samico não seria uma produção erudita que se aproxima de uma cultura popular, como o Movimento Armorial anuncia e muitos comentadores replicam. Trata-se de uma das formas de invenção de uma cultura popular a partir de uma cultura erudita. 0 que aparece como inspiração deveria, antes, ser visto como invenção. É evidente que Suassuna não inventou a xilogravura. Ela já existia nos folhetos de cordel independentemente de sua maquinação Armorial. Contudo, a eleição de um determinado tipo de ilustração como elemento diacrítico de toda uma suposta cultura genuinamente popular e brasileira não está dada nas imagens por elas mesmas. Segundo as pesquisas de Ramos, a xilogravura nem ao menos se configurava como a mais representativa das técnicas empregadas pelos cordelistas. Para que a gravura em madeira - um bem cultural produzido e inserido em um circuito específico por um determinado grupo social - fosse transformada "na cultura popular" ou "na cultura genuinamente brasileira" foi 
preciso mais do que madeira, goivas, tinta, papel e a criatividade do povo. Foram necessárias ferramentas discursivas eficazes e posições sociais que permitiram nomear tal produção como a mais representativa do "espírito do povo". Essas ferramentas, além de muitas outras, Ariano Suassuna soube manusear. Ao comentar as gravuras de Samico, o líder do Movimento Armorial diz:

Só julgará que estes assuntos não nos pertencem quem não sabe que Israel e os países árabes são também o Brasil. Que Samico, incluindo santos e profetas em seu mundo, está apenas, mais uma vez, sendo fiel à mais verdadeira linhagem da arte brasileira desde seus inícios. E sobretudo quem não sabe que o sertão é o mundo. (SUASSUNA, 2005, p. 76).

Samico colabora para a criação dessa concepção do "popular" na medida em que se baseia nessa iconografia eleita por Suassuna e deixa de utilizar os volumes e perspectivas das gravuras executadas em seu período "noturno" para criar imagens chapadas, sem distinção de planos e volumes tal como nas gravuras "genuinamente populares".

Ariano Suassuna afirma ainda:

O segredo delas [as gravuras geniais de Samico] constituiu em voltar o gravador a certos processos que os novidadeiros e repetidores julgavam esgotados. Em voltar ao uso do material mais puro, mais nobre e mais primitivo da gravura, a madeira. Em regressar às raízes, recriando com a liberdade e a imaginação do gênio, o espírito e as formas da xilogravura de seu povo. Em contornar as figuras de um limpo traço escuro que se destaca nos espaços brancos, por entre grandes massas negras ou tramas delicadamente interpostas; e toques de vermelho, verde, azul ou amarelo, que a gravura popular não usava e que, depois dele, num fecundo intercâmbio, passou a empregar como uma paga do sopro inicial (SUASSUNA, 2005, p. 78).

Para Suassuna, é o espírito de seu povo que informa Samico em sua ação criativa. Daí viria o poder de suas imagens. Poder tão genuíno que é o único capaz de alterar a própria gravura popular (que antes não usava cores) sem deturpar o seu espírito original. 0 uso da cor pela gravura "popular", um "fecundo intercâmbio", pode ser lido também como mais um forte indício da invenção da gravura popular pelos artistas chamados eruditos. Assim como inventaram que a madeira era o suporte mais "nobre e primitivo", inventam também o uso da cor por parte dos artistas ditos "populares”. A ideia de circulação cultural, tão cara a Carlo Ginzburg (1998) na sua análise do caso do Menocchio, tem aqui um paralelo possível. A relação que se estabelece entre produtores de cordel e intelectuais faz parecer uma simples circulação entre cultura erudita e cultura popular. No entanto, como Ginzburg ressalta para o seu caso, essa relação é dialógica e, portanto, há uma assimetria de poder entre as partes. $\mathrm{Na}$ medida em que intelectuais elegem essa manifestação popular como a quintessência da "cultura genuinamente brasileira", induzem o próprio povo a produzir nessas novas convenções, exercendo sobre ele um poder dissimulado, pois os resultados são tidos como manifestações culturais genuínas e espontâneas do próprio povo. Novamente semelhanças forçadas, difusões conflituosas se colocam em outra escala.

Suassuna e grande parte da fortuna crítica reforçam as supostas vinculações dos trabalhos de Samico com um universo tido como popular. Assim operando, essenciali- 
zam a "cultura popular" como se ela existisse de forma independente e apartada das operações executadas por intelectuais altamente engajados em sua construção como trunfos em rede de relações nada populares.

Samico e Suassuna, ao fazerem referência a uma iconografia existente sobretudo na produção gráfica de Juazeiro do Norte, constroem essa mesma iconografia como a expressão legítima da cultura ou do "espírito do povo”. Essa operação valoriza ambos os lados da relação. A xilogravura "popular”, antes desvalorizada até mesmo entre os cordelistas, passa a ser vista como uma arte nobre. Os trabalhos de Samico, antes vistos pelo próprio artista como pouco ligados a uma arte local e brasileira, passam a ser identificados como inspirados no que há de mais "genuíno" e "espontâneo" em nossa cultura. É a sugestão do parágrafo final do texto de Ariano Suassuna que, numa referência explícita a Goeldi e Abramo, critica os "nossos meros imitadores":

É, então, por ter encontrado seu caminho pessoal dentro da maravilha que é a arte popular brasileira, que o mundo de Samico aparece com tanta força e novidade, harmonizados, nela, todos os contrastes e violências. Isto no panorama cinzento e monótono dos nossos meros imitadores, onde quando ele começou, somente exercitavam os maneirismos de uma "vanguarda" de segunda-mão e onde hoje, graças a ele, os pássaros de fogo do sol nordestino fulgem como estrelas nas torres e castelos do Reino do Sertão do Brasil. (SUASSUNA, 2005, p. 80).

\section{0 mestre Samico}

Durante seu período de estudos em São Paulo e Rio de Janeiro, entre 1957 e 1959, Samico produziu 56 matrizes. A partir dos anos 1970, já morador de Olinda, sua produtividade passa para cerca de uma matriz por ano. Esse ritmo mais lento é interpretado pela sua fortuna crítica como necessário para a criação de imagens tão elaboradas e complexas. 0 caráter artesanal (explícito na precisão dos entalhes, das junções das cores, no equilíbrio e na simetria das composições, na “mitologia” envolvida etc.) é reforçado pelo tempo utilizado para a produção de uma única matriz. Materialmente, Samico sobreviveu com outros empregos, como o de professor na Universidade Federal da Paraíba, mas certamente o controle da sua produção também contribuiu para a manutenção de sua aura como um artista consciencioso, inapto ao ritmo industrial imposto pelo mercado e pela modernidade.

Sua aura de artesão foi tão impregnada pela própria criação do popular que não é raro caracterizarem Samico como um “mestre artesão" incorporado pelo mundo da arte contemporânea. É o caso do crítico Guy Amado. No texto de abertura do livro resultado do programa Rumos Artes Visuais 2008/2009, promovido pelo Itaú Cultural, após dizer que é uma prática corrente artistas eruditos se apropriarem de referências populares, Amado afirma:

Observa-se também, em grau mais arrefecido, uma movimentação de sinal invertido, em que artesãos são deslocados do âmbito de uma fatura comprometida com as tradições locais para o chamado circuito da arte contemporânea. Nessa situação, um nome emblemático é o de Mestre Didi, artesão baiano que teve sua obra arrebatada do universo de uma fatura local, voltada especificamente para uma função cerimonial (produção de objetos ioruba) e subitamente inserida no grande circuito de bienais e galerias de arte contemporânea. Ocorre-me ainda uma outra 
situação "intermediária", quando a produção do artista se situa num terreno híbrido: assumida e legitimamente calcada num repertório visual popular local, mas que por uma qualidade de sutil refinamento e erudição atende também a demandas do grande circuito. É o caso por exemplo de Gilvan Samico, mestre gravador de Olinda, produzindo meticulosamente e silenciosamente há décadas e tendo sua produção largamente apreciada (e consumida) pelo público e por colecionadores de arte contemporânea. Idiossincrasias e pulsões poéticas à parte, tanto um como outro seguem como referências de artistas que conjugam em graus diversos $o$ repertório popular, do qual não abrem mão, e a circulação de sua produção no circuito da arte contemporânea (AMADO, 2009, p. 24).

Para além da caracterização de Mestre Didi como um artesão baiano parecer um tanto simplista - afinal, sua origem familiar e alianças sociais dificilmente o vinculariam exclusivamente a uma camada "popular" -, Guy Amado descreve Samico, o aluno de Abelardo da Hora, Lívio Abramo, Oswaldo Goeldi, funcionário de Aloísio Magalhães, professor da Universidade Federal da Paraíba, como um "mestre gravador de Olinda”, que produz "meticulosamente e silenciosamente há décadas". 0 autor enfatiza que a intenção de Samico seria um circuito popular local "mas que por uma qualidade de sutil refinamento e erudição atende também a demandas do grande circuito". Ora, até onde se pôde apurar, o foco do diálogo de Samico não está voltado para os gravadores de Juazeiro do Norte. Os interlocutores que têm em mente são seus professores e colegas "eruditos" e não os gravadores "populares” que utilizou como fonte. A própria formulação do Movimento Armorial visa à criação de uma arte erudita a partir da arte popular. 0 objetivo é construir uma "grande arte" e não se manter no campo do "popular".

Cláudio Mubarac e Priscila Sachettin, curadores da exposição Gilvan Samico - primeiras estórias, realizada no Centro Universitário Maria Antônia, também reconhecem essa classificação de "popular" que ronda a obra do artista. Diziam eles no texto de parede:

Não é estranho, portanto, que ele tenha se declarado um artista erudito. Pode-se entender essa autodefinição não como negativa do popular, evidentemente forte em sua obra, mas como afırmação de um conhecimento amplo, advindo de múltiplas fontes, inclusive da tradição europeia (esse diálogo entre erudito e popular, vale lembrar, atravessa toda a história da gravura) ${ }^{7}$.

Por que Samico precisou declarar-se um artista erudito? Dado sua trajetória, não era um fato óbvio? Ou o simples fato de ser pernambucano, morar em Olinda, gravar em madeira temas “populares” já o colocariam necessariamente como artista popular?

\section{Considerações finais}

As formulações de Pierre Bourdieu (1989) a respeito de movimentos regionalistas ajudam também a compreender

7. A íntegra desse texto pode ser recuperada no site do Centro Universitário Maria Antônia. (Disponível em: <http://mariantonia.prceu.usp.br/?q=exposicao/gilvan-samico>. Acessado em: 14/11/2013). 
os mecanismos frequentemente utilizados para a positivação simbólica de áreas periféricas, tais como os empreendidos por Samico e demais artistas pernambucanos. 0 sociólogo francês desenvolve a tese de que a reivindicação regionalista é uma resposta à estigmatização que produz a "região" enquanto "província”. Se o "centro" atribui valor de "província" a uma região afastada simbólica e socialmente dele, o movimento regionalista responde a esta estigmatização tornando essa imagem positiva. 0 “centro" detém capital material e simbólico que a "província” não possui e, portanto, é capaz de detratá-la como região menor. É dessa existência estigmatizada que surgem as reivindicações regionalistas na busca da inversão dos sinais negativos do estigma imputado pelo “centro". Entretanto, essa resposta positivada não elimina a relação politicamente tensa entre o "centro" e a "província”, relação expressa aqui na trajetória de Samico. Seu incômodo com sua arte pouco brasileira e sua busca por algo mais "nosso", assim como a construção de uma estética popular andam pari pas$s u$ com as formulações críticas a respeito de sua obra, identificando-o cada vez mais com o universo popular até o completo borramento de fronteiras com a denominação de “mestre gravador". Nessa espécie de geopolítica da produção e apreciação de obras de arte, as qualificações estéticas parecem reproduzir as assimetrias políticas e econômicas.

José Claudio, pintor e memorialista do grupo Atelier Coletivo, ao reconstruir os embates de sua geração, fez, espontaneamente, a associação da condição do seu grupo com uma anedota. Em entrevista, lembrou Miguel Arraes intervindo numa conversa entre ele e o filho, Maurício Arraes, contando que: na China, depois da vitória, Mao Tse-Tung quis conhecer aqueles capitães que lutaram com ele nas diversas regiões, naqueles rincões. Ele nunca tinha conversado com esses homens, só sabia da existência deles. E a primeira coisa que ele fez quando tomou o poder foi conhecer essa gente. Ele quis conhecer um por um. Aí chegou um desses comandantes lá dos confins e a primeira pergunta que Mao Tse-Tung fez a ele foi "qual é sua religião”. 0 cara até ficou chocado, pensando que Mao Tse-Tung estaria o considerando, por ser de uma região distante, que ele não entendesse nada de política, que ele fosse um cara atrasado. Aí ele respondeu: "Excelência, eu sou um marxista”, como se por ser marxista não pudesse ter religião. Mao Tse-Tung disse; "você está errado. Se você não tiver a religião do seu povo, você nunca poderá dialogar com ele." (SILVA; DIMITROV, 2011).

$\mathrm{Na}$ historieta contada por José Cláudio, aos olhos do comandante chinês, Mao Tse-Tung o via, por ser originário de uma região afastada, como um arcaico que não teria sido iluminado pelo marxismo e, portanto, um religioso. Para provar que não era um provinciano, o comandante afirmou vivamente suas convicções comunistas. 0 reconhecimento, porém, não se dava nessa chave. Não era o marxismo que interessava a Mao Tse-Tung, seu interlocutor socialmente legitimado, e sim a especificidade de cada região, a religião do povo de cada um dos rincões da China e, assim, a provincialidade do comandante.

José Cláudio, Wellington Virgolino e Gilvan Samico (além de Lula Cardoso Ayres, Cícero Dias, Francisco Brennand...) em alguns momentos reagiram vivamente aos interlocutores, enfatizando sua formação, seu conhecimento da "grande arte". Mas o 
diálogo não estava estabelecido nessa lógica justamente porque eles não eram iguais: eram oriundos da periferia, da região. $\mathrm{Na}$ conversação dialógica, as posições dos interlocutores não são simétricas, o que faz os artistas pernambucanos - ao se inserirem num debate que extrapola as fronteiras do Estado - ocuparem posição semelhante à do comandante chinês frente ao Grande Mao. Num movimento sutil desse aparente diálogo que esconde as diferenças de poder, a valorização do regional, do popular, do ingênuo aparece como vontade própria, como convicção, e adequação à natureza mais íntima, ao impulso criativo do artista. Mao olha o comandante como um diferente, o comandante, num primeiro momento, revolta-se por se considerar um igual, mas depois é como se assumisse a suposta especificidade da região por desejo próprio. E a desigualdade de poder surge como diferença entre iguais. 0 impulso criativo do artista torna as imposições externas quase imperceptíveis.

Semelhanças forçadas, difusões conflituosas. 0 centro impõe aos artistas da periferia certos limites de atuação; os associam ao popular, apagam suas referências eruditas, limitam-os, em suas análises, a universos expressivos específicos mesmo que utilizando-se de técnicas difundidas pelos centros. Já os artistas, por sua vez, tendem a reforçar essas posições como, talvez, uma alternativa positiva de existência. 


\section{Imagens}

Figura 1 - Gilvan Samico. Pescadores de Siri na Ponte Velha. 1952.0́leo sobre hardboard. 71 x 59 cm. Reproduzido na Enciclopédia Virtual do Instituto Itaú Cultural (2013).

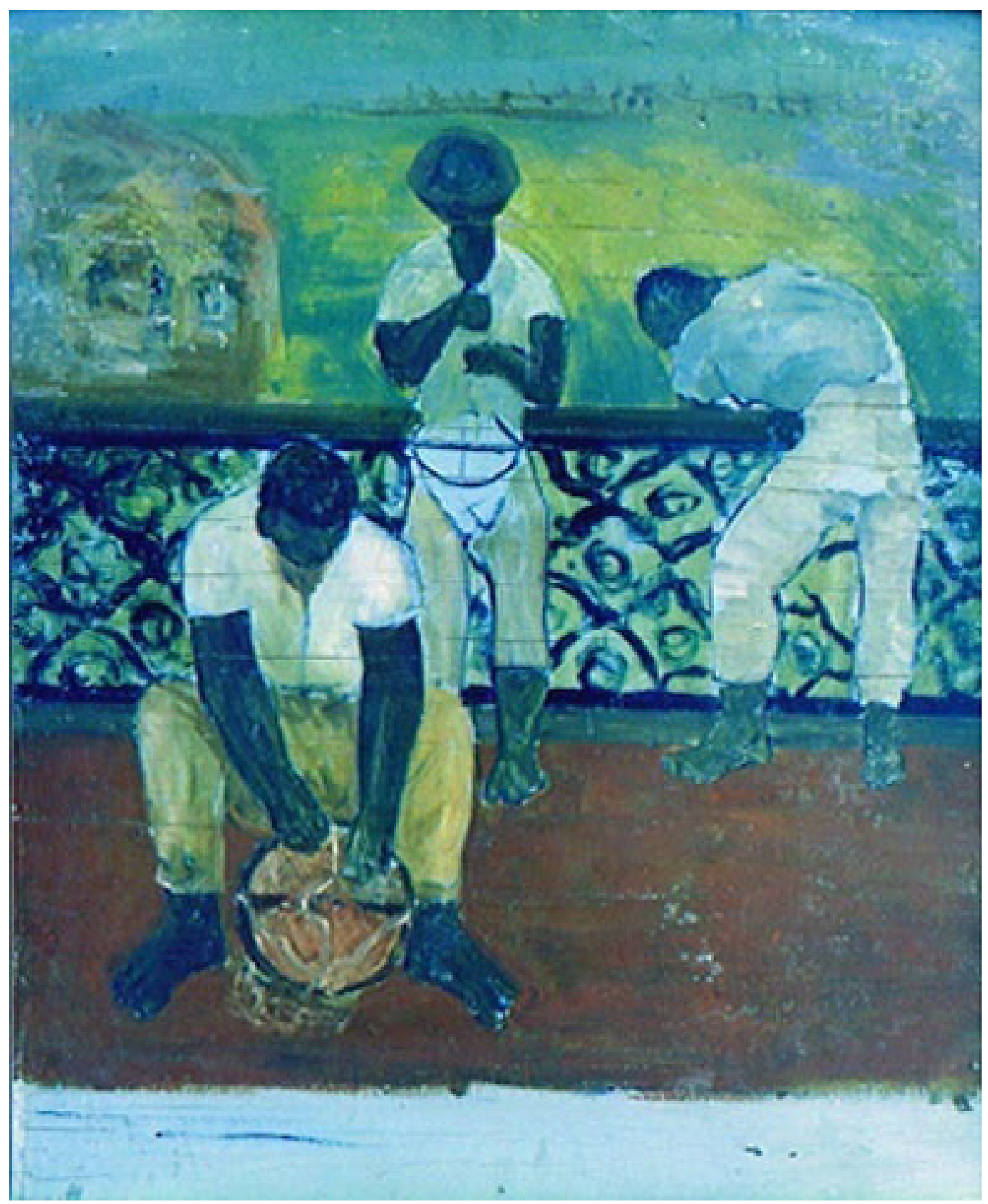


Figura 2 - Gilvan Samico. Trabalhadores. óleo s/ chapa de madeira industrializada, ass. e dat. 1954 inf. esq. $79,5 \times 73,5 \mathrm{~cm}$.

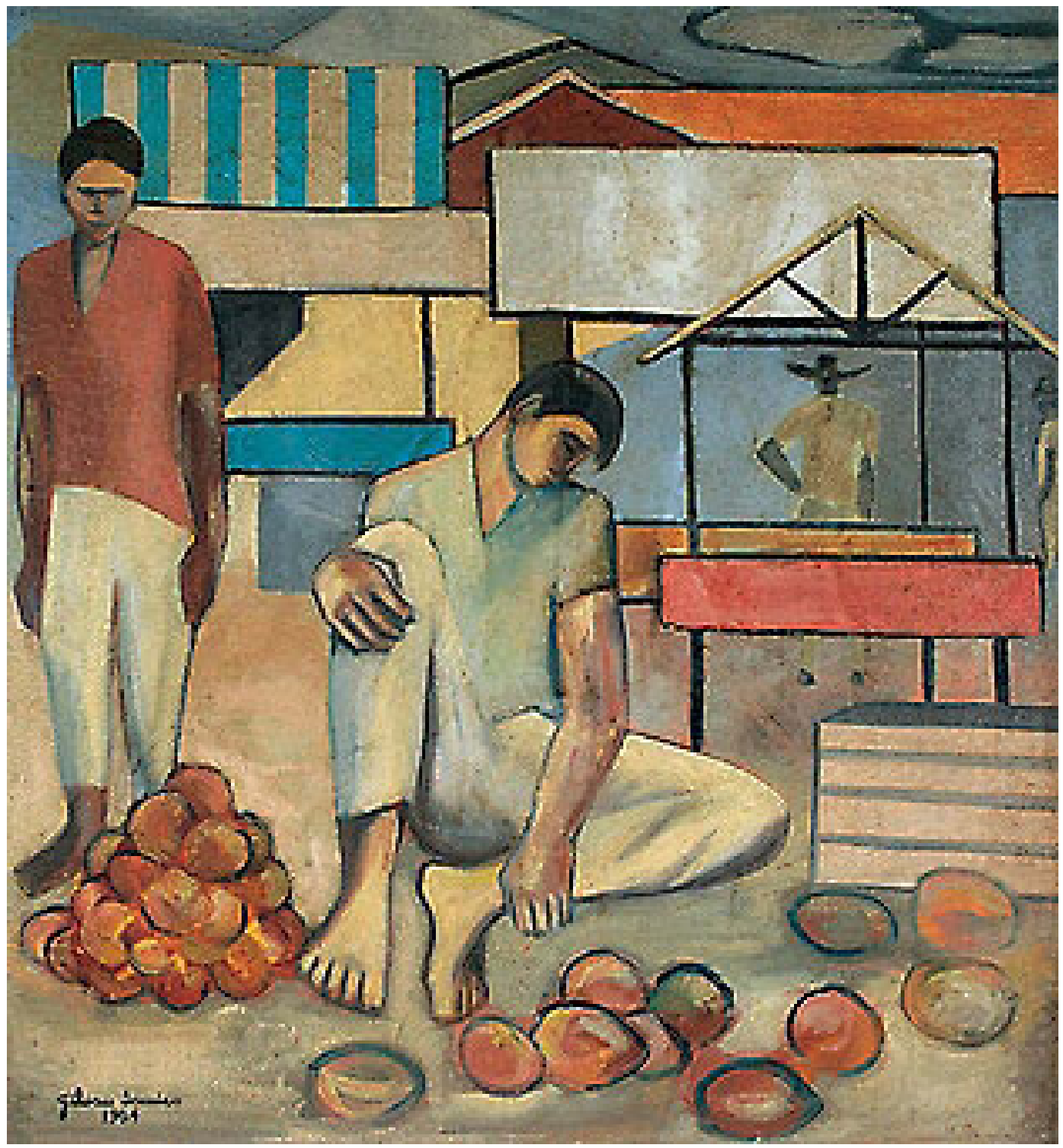


Figura 3 - Gilvan Samico. A Mão. 1957, xilogravura, 28,5 x 28,5 cm. Reproduzido na Enciclopédia Virtual do Instituto Itaú Cultural (2013).

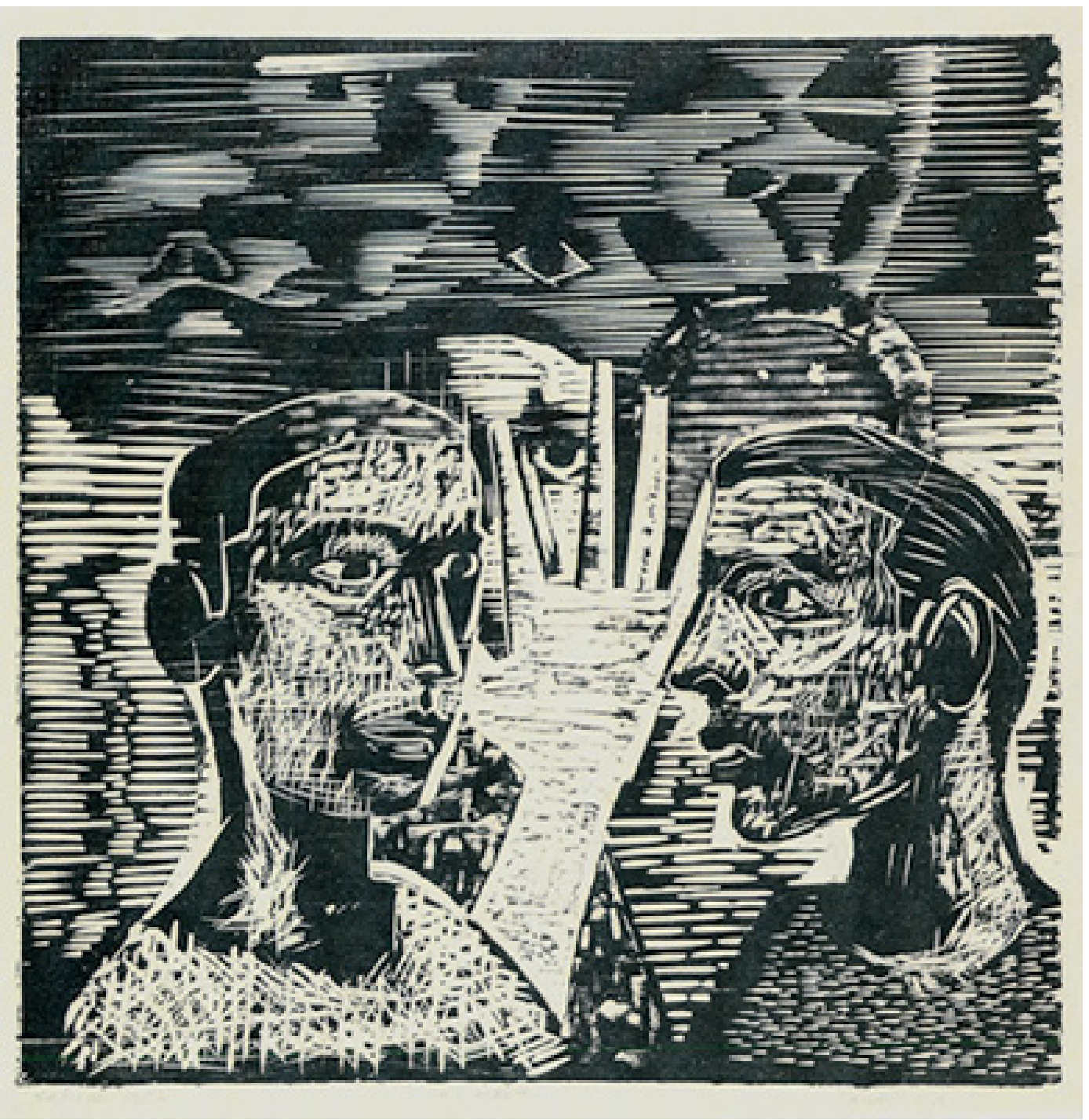


Figura 4 - Gilvan Samico. Menina dos Currupios. 1958, xilogravura, 23,7 x $21 \mathrm{~cm}$. Reproduzido na Enciclopédia Virtual do Instituto Itaú Cultural (2013).

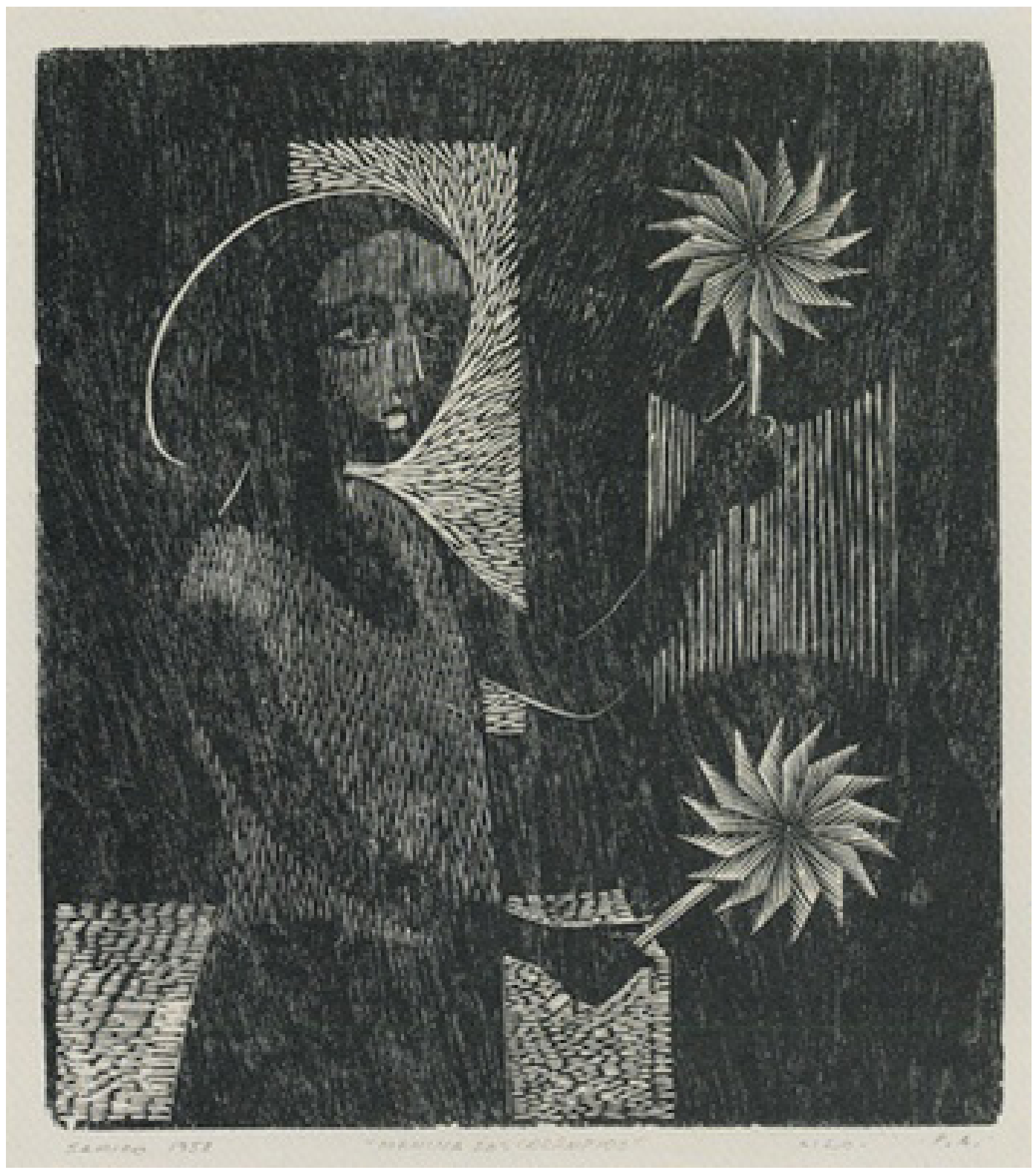


Figura 5 - Gilvan Samico. Leitura na Praça. 1958, xilogravura, 21 × 23,5 cm. Reproduzido na Enciclopédia Virtual do Instituto Itaú Cultural (2013).

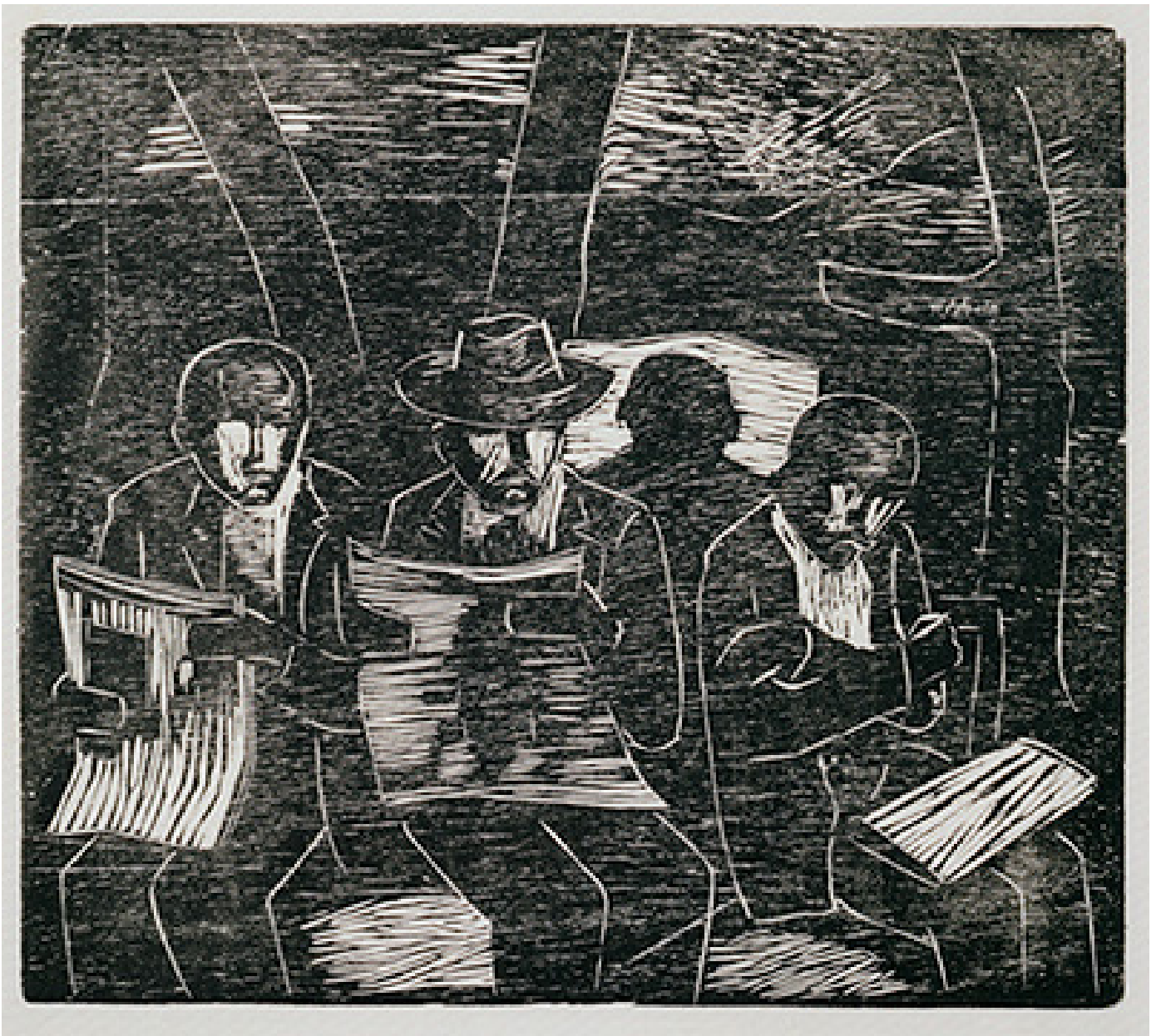


Figura 6 - Samico, Dama com luvas. 1959, xilogravura, 36 × 29,6 cm. Reprodução fotográfica do catálogo da exposição "Samico: do desenho à gravura", Pinacoteca do Estado de São Paulo, 2004. Disponível em: <http:// artepopularbrasil.blogspot.com.br/2011/09/samico.html>. Acessado em 20/11/2013.

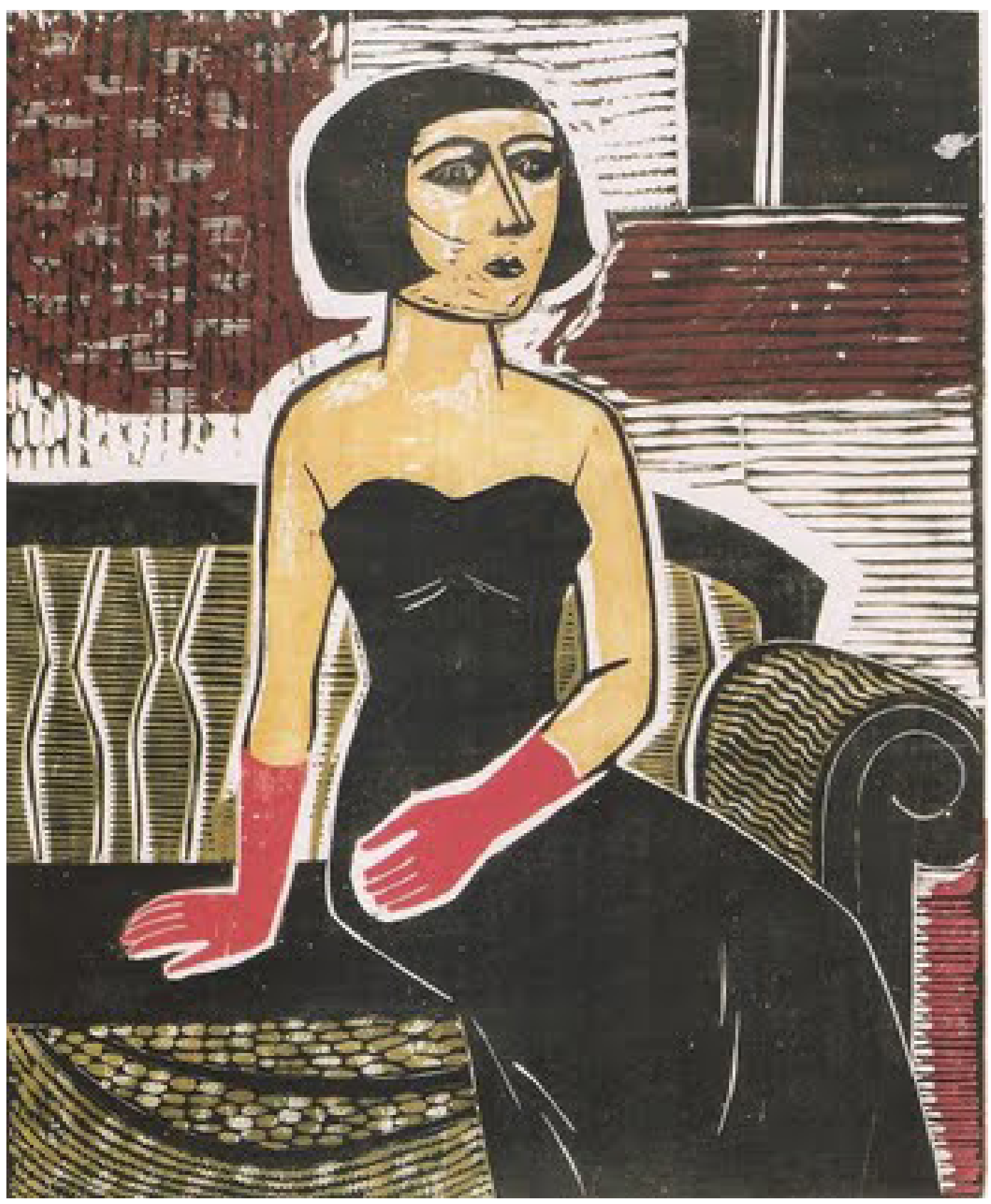


Figura 7 - Samico, Gilvan. Tentação de Santo Antonio, 1962. xilogravura. 34 x $45 \mathrm{~cm}$. Reproduzido na Enciclopédia Virtual do Instituto Itaú Cultural (2013).

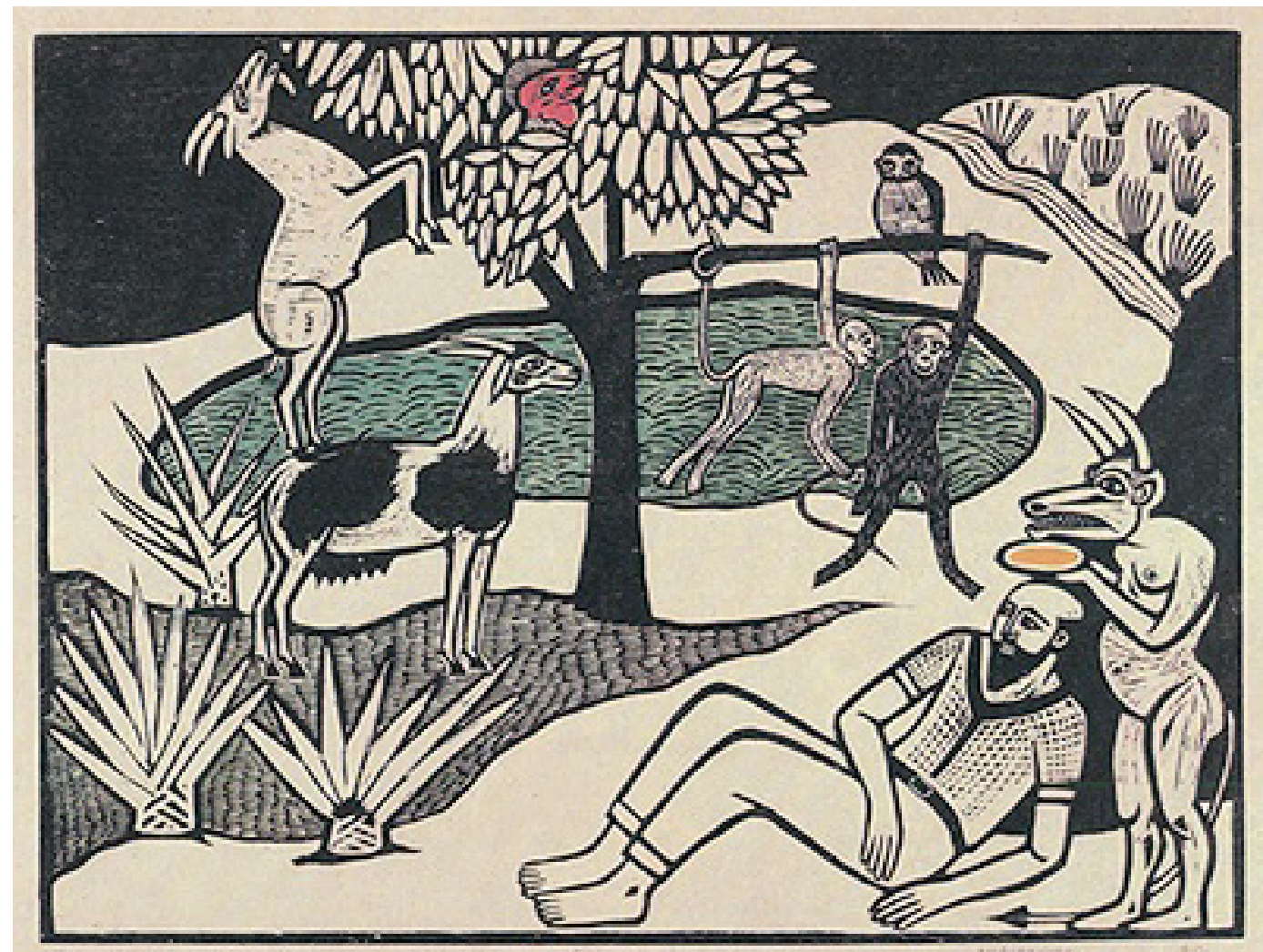


Figura 8 - Gilvan Samico. A luta dos anjos. 1968. xilogravura.54,8 x $33 \mathrm{~cm}$. Reproduzido na Enciclopédia Virtual do Instituto Itaú Cultural (2013).

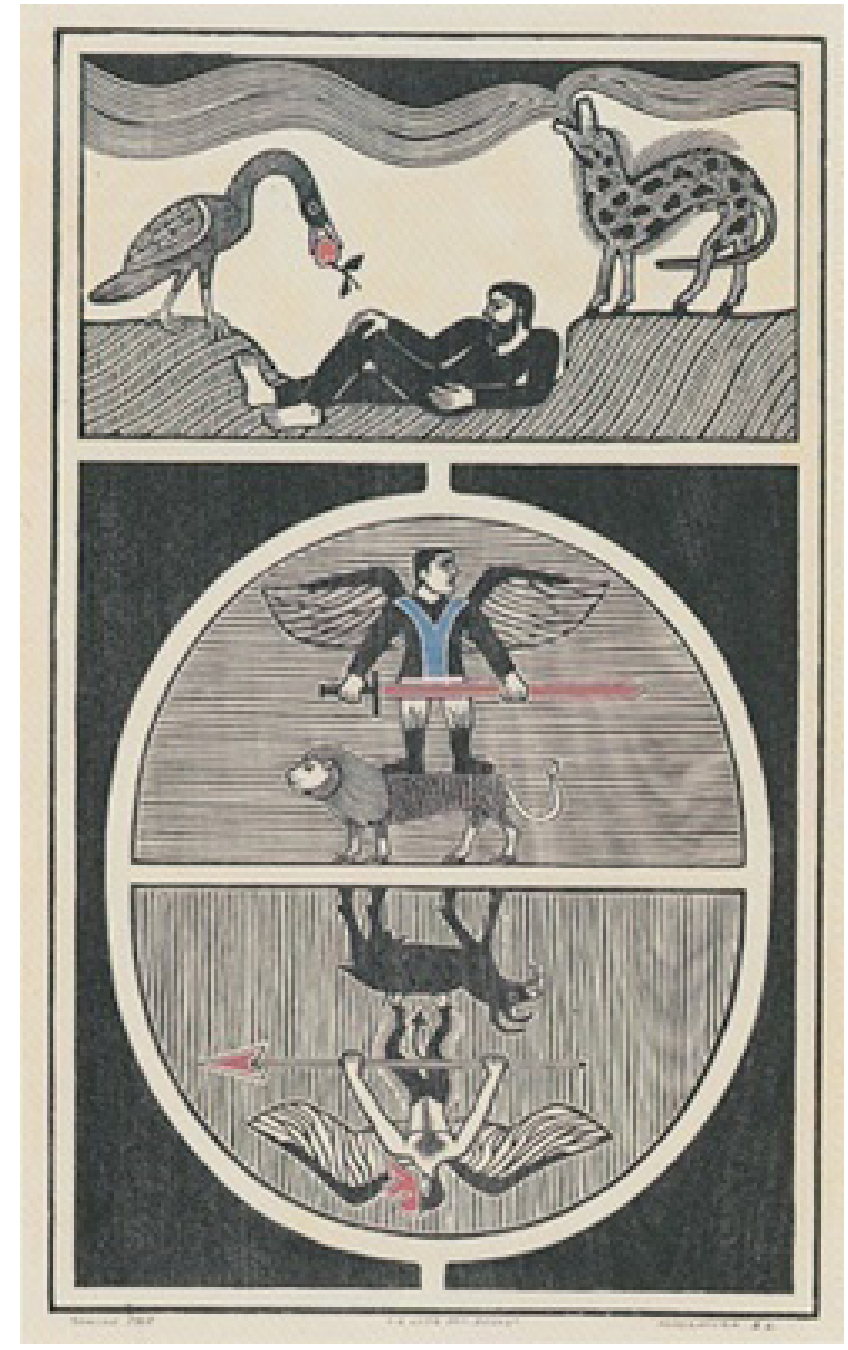


Figura 9 - Gilvan Samico. 0 Encontro, 1978. xilogravura. 73,5 x 50 cm. Reproduzido na Enciclopédia Virtual do Instituto Itaú Cultural (2013).

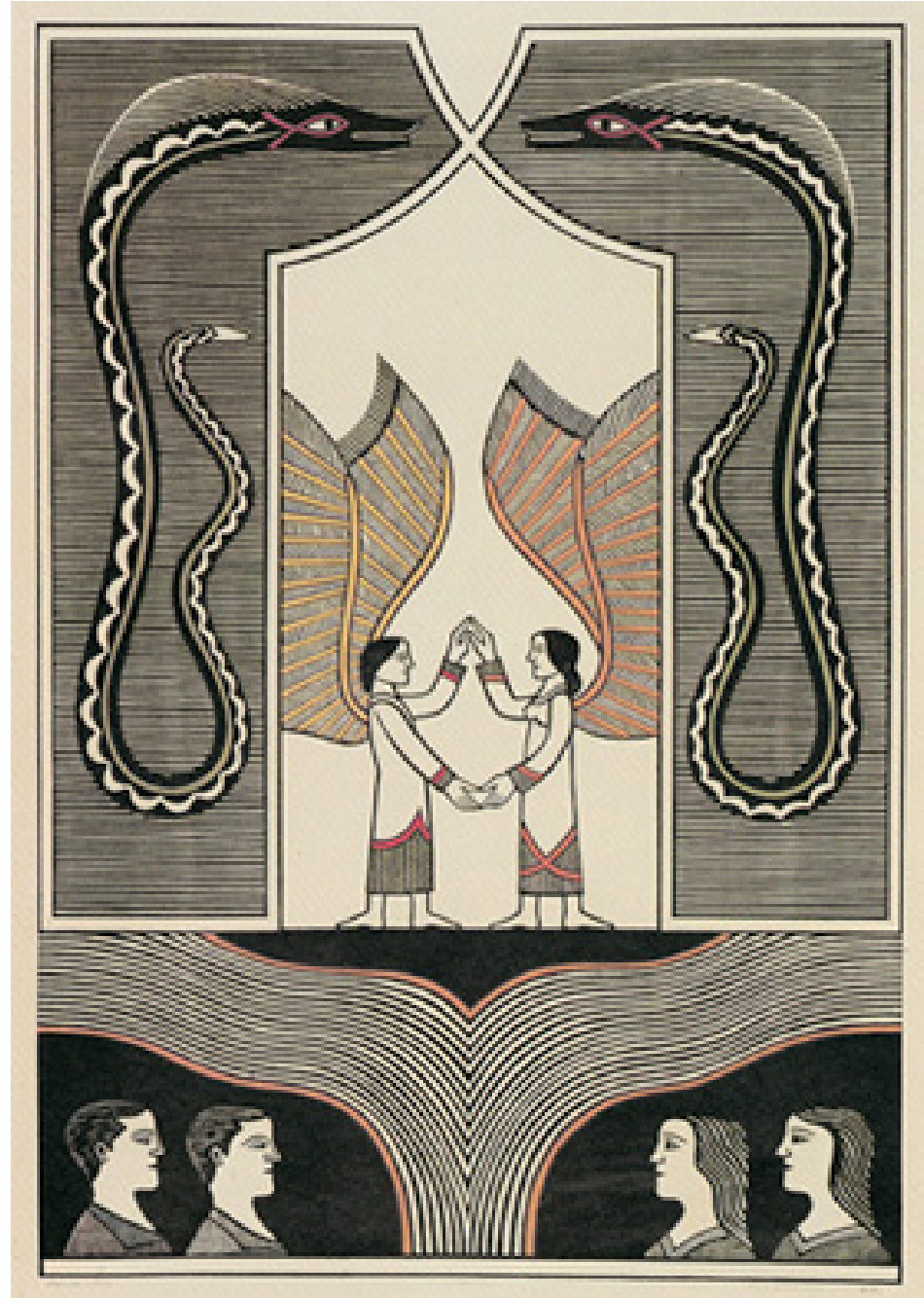




\section{Referências Bibliográficas}

AMADO, G. Longitudes, (L)atitudes e regionalismos. In: RUMOS ITAÚ CULTURAL (Ed.). Trilhas do desejo: a arte visual brasileira. São Paulo: Editora Senac São Paulo : Itaú Cultural, 2009. p. 19-26.

AMARAL, A. A. Arte Para Quê: a preocupação social na arte brasileira 1930-1970. 3. ed. São Paulo: Estudio Nobel, 2003.

ANDERSON, B. Comunidades imaginadas: reflexões sobre a origem e a difusão do nacionalismo. São Paulo: Companhia das Letras, 2008.

ANJOS JR., M. dos. 0 Outro Lado do Rio. In: ANJOS JR., M. DOS (Ed.). Gilvan Samico. Artistas do MAMAM. Recife: Museu de Arte Moderna Aloísio Magalhães, 2005. p. 6-13.

BOURDIEU, P. A identidade e a representação: elementos para uma reflexão crítica sobre a idéia de região. In: BOURDIEU, P. O Poder Simbólico. Rio de Janeiro: Bertrand, 1989. p. 107-132.

FARIAS, A. 0 oráculo de Olinda. In: ANJOS JR., M. DOS (Ed.). Gilvan Samico. Artistas do MAMAM. Recife: Museu de Arte Moderna Aloísio Magalhães, 2005. p. 14-27.

GINZBURG, C. 0 queijo e os vermes: o cotidiano e as idéias de um moleiro perseguido pela Inquisição. São Paulo: Companhia das Letras, 1998.

GULLAR, F. Sonho e Rigor. In: ANJOS JR., M. DOS (Ed.). Gilvan Samico. Artistas do MAMAM. Recife: Museu de Arte Moderna Aloísio Magalhães, 2005. p. 57-58.

HOBSBAWM, E. J. Introdução: A Invenção das Tradições. In: HOBSBAWM, E. J. ; RANGER, T. (Orgs.). A Invenção das Tradições. São Paulo: Paz e Terra, 1997. p. 9-23.

INSTITUTO ITAÚ CULTURAL. Enciclopédia Itaú Cultural de Artes Visuais. Disponível em: <http:// www.itaucultural.org.br/aplicexternas/enciclopedia_ic/index.cfm>. Acesso em: 20 nov. 2013.

LEAL, W. B. 0 vôo da imaginação. In: ANJOS JR., M. DOS (Ed.). Gilvan Samico. Artistas do MA-
MAM. Recife: Museu de Arte Moderna Aloísio Magalhães, 2005. p. 28-44.

MORETTI, F. Atlas do romance europeu: 18001900. São Paulo: Boitempo, 2003.

MYRDAL, G. Development and Under-development: A Note on the Mechanism of National and International Economic Inequality. Cairo: National Bank of Egypt, 1956.

RAMOS, E. Ariano Suassuna et la gravure populaire brésilienne ou La (dé)formation d'une pensée critique. Plural Pluriel: Revue des cultures de langue portugaise, v. 1, n. 1, 2008. Disponível em: $<$ http://www.pluralpluriel.org/index.php?option=com_contentEtview=articleEtid=93:ariano-suassuna-et-la-gravure-populaire-bresilienne-ou-ladeformation-dune-pensee-critique-Etcatid $=51: \mathrm{nu}$ mero-01Ettemid=55>. Acesso em: 14 maio. 2010.

SAMICO, G.; FERNANDES, E. M. Entrevista com Gilvan Samico. Recife: CEHIBRA/FUNDAJ. mimeo, 2008.

SCHWARZ, R. Um mestre na periferia do capitalismo: Machado de Assis. São Paulo: Livraria Duas Cidades : Editora 34, 2000a.

SCHWARZ, R. Ao Vencedor as batatas: forma literária e processo social nos inícios do romance brasileiro. São Paulo: Duas cidades : Ed. 34, 2000b.

SILVA, J. C. da; DIMITROV, E. Entrevista com José Cláudio. Recife: mimeo, 2011.

SUASSUNA, A. A gravura de Samico. In: ANJOS JR., M. DOS (Ed.). Gilvan Samico. Artistas do MAMAM. Recife: Museu de Arte Moderna Aloísio Magalhães, 2005. p. 72-80. 
RESUMO

Este artigo reconstrói a trajetória de Gilvan Samico mobilizando algumas de suas produções artísticas e apreciações de críticos de arte. 0 intuito é evidenciar a relação assimétrica entre produtor e críticos, o que impacta nas opções estéticas e na forma como elas são interpretadas. A circulação deste artista entre Recife, São Paulo, Rio de Janeiro e Olinda imprime aspectos específicos, formais e temáticos às suas gravuras. A incorporação de uma gramática visual difundida pelos centros, a busca por uma temática vinculada a uma noção de brasilidade e, ao mesmo tempo, a forma como os críticos analisam suas produções vinculando-as ao universo popular evidencia uma relação específica entre centro e periferia na produção artística brasileira.

\section{PALAVRAS-CHAVE}

Arte Brasileira. Sociologia da arte. Centro e periferia. Arte pernambucana. Circulação intelectual.

\section{ABSTRACT}

This article traces a trajectory of Gilvan Samico mobilizing some of its artistic productions and critical assessments of his art. The aim is to highlight the asymmetrical relationship between producer and critics, which impacts on aesthetic options and how they are interpreted. The circulation of this artist from Recife, São Paulo, Rio de Janeiro and Olinda print specific aspects, formal and thematic in his engravings. The incorporation of a visual grammar diffused by the centers, the search for a theme linked to a notion of Brazilianness and, at the same time, the way critics analyze their productions by linking them to the popular universe shows a specific relation between center and periphery in the Brazilian artistic production.

\section{KEYWORDS}

Brazilian Art. Sociology of art. Center and periphery. Intellectual circulation. Art in Pernambuco. 